\title{
Pemanfaatan Google Speech to Text Untuk Aplikasi Pembelajaran Kamus Bahasa Sunda Pada Platform Mobile Android
}

\author{
${ }^{1}$ Rangga Gelar Guntara, ${ }^{2}$ Asep Nuryadin, ${ }^{3}$ Benyamin Hartanto \\ ${ }^{1.2 .3}$ Bisnis Digital, Universitas Pendidikan Indonesia, Indonesia \\ ranggagelar@upi.edu, asep.nuryadin@upi.edu, benyaminhartanto@upi.edu
}

\begin{abstract}
ARTICLE INFO
Article History:

Received : 06-04-2021

Revised : 23-04-2021

Accepted : 01-05-2021

Online : 04-05-2021

Keywords:

Android, Bahasa Sunda, Aplikasi, Speech To Text, Kamus
\end{abstract}

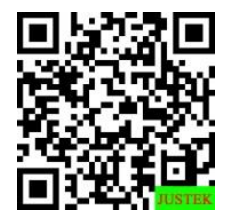

\begin{abstract}
Abstract: Sundanese language is one of the Malayo-Polynesian languages which are a subgroup of the Austronesian language family. There are at least 38 million people speaking this language and it becomes the second-largest language after the Javanese language in terms of the first language. However, the Sundanese language is considered an endangered language as according to a study conducted by West Java Province Language Center, only $40 \%$ of children in West Java who know and can speak the Sundanese language. Therefore, it is crucial to find ways of improving people's interest in learning the Sundanese language one of which by making the learning process easy and enjoyable. In this study, an interactive Sundanese language learning application named RuangBasa has been built by using Google Speech to Text technology. The software development method used was the waterfall method. The Alpha test results showed that all features available in the application could run as expected. In addition, the results of the user reviews on the Google Play Store, in which they provided comments on the application after they had used it, had generated the beta test results. Based on the user review results, the application got a score of 4.8 out of a total of 27 users.
\end{abstract}

Abstrak: Bahasa Sunda adalah salah satu dari bahasa-bahasa MelayuPolinesia yang merupakan cabang dari rumpun bahasa Austronesia. Setidaknya ada 38 juta orang yang menuturkan bahasa ini dan menjadi bahasa Ibu dengan penutur terbanyak kedua di Indonesia setelah bahasa Jawa. Namun, bahasa Sunda dianggap bahasa yang terancam punah karena berdasarkan penelitian yang dilakukan Balai Bahasa Provinsi Jawa Barat, hanya 40\% anak-anak di Jawa Barat yang tahu dan dapat berbicara bahasa Sunda. Oleh karena itu, sangat penting untuk menemukan berbagai cara untuk meningkatkan ketertarikan masyarakat untuk belajar bahasa Sunda, salah satunya dengan menjadikan proses belajar menjadi mudah dan menyenangkan. Pada penelitian ini, sebuah aplikasi pembelajaran bahasa Sunda yang interaktif bernama RuangBasa dibangun dengan memanfaatkan teknologi Google Speech to Text. Metode pengembangan perangkat lunak yang digunakan adalah metode waterfall. Hasil pengujian Alpha (black box), menunjukkan semua fitur yang tersedia pada aplikasi berjalan sesuai yang diharapkan. Selain itu, hasil review pengguna di Google Play Store, di mana mereka memberikan komentar pada aplikasi setelah mereka menggunakannya, telah menghasilkan hasil pengujian beta. Dari hasil review para pengguna, aplikasi mendapatkan skor 4,8 dari total 27 pengguna. 


\section{A. LATAR BELAKANG}

Bahasa Sunda adalah sebuah bahasa dari cabang Melayu-Polinesia dalam rumpun bahasa Austronesia. Bahasa ini dituturkan oleh setidaknya 38 juta orang dan merupakan bahasa Ibu dengan penutur terbanyak kedua di Indonesia setelah bahasa Jawa. Bahasa Sunda dituturkan dihampir seluruh provinsi Jawa Barat dan Banten, serta wilayah barat Jawa Tengah mulai dari Kali Brebes (Sungai Cipamali) di wilayah Kabupaten Brebes dan Kali Serayu (Sungai Ciserayu) di Kabupaten Cilacap, di sebagian kawasan Jakarta, serta di seluruh provinsi di Indonesia dan luar negeri yang menjadi daerah urbanisasi Suku Sunda (Pribadi et al., 2016)

Namun, seiring dengan perkembangan zaman, masyarakat sering mengabaikan bahasa ibu atau daerah masing-masing, termasuk bahasa Sunda. Bahasa Sunda terancam punah, hanya sekitar 40 persen anak-anak di Jawa Barat (Jabar) yang mengetahui dan bisa berbahasa Sunda. Data ini diperoleh dari hasil penelitian Balai Bahasa Provinsi Jawa Barat (BBPJB) Kementerian dan Kebudayaan RI (Mulyati et al., 2019). Penyebabnya tiada lain adalah keberadaan bahasa Sunda itu sendiri yang sangat jarang digunakan lagi oleh masyarakat Sunda, terlebih lagi masyarakat wilayah perbatasan, semisal Kota Bogor yang secara geografis dan kultural berbatasan dengan Betawi (Pramswari, 2014).

Upaya mempertahankan bahasa sunda dirasa perlu melibatkan kemajuan teknologi sekarang ini. Menurut (Ariyati \& Misriati, 2016) menyatakan bahwa "Dalam dunia Pendidikan suatu metode pembelajaran dapat dihadirkan dengan menggunakan alat peraga pembelajaran atau sering dikenal media pembelajaran". Media pembelajaran adalah sebuah alat yang berfungsi dan digunakan untuk menyampaikan pesan pembelajaran, pengajar dan bahan ajarnya (Hakim, 2020). Komunikasi tersebut dapat berjalan dengan bantuan sarana untuk menyampaikan pesan. Bentuk stimulus yang dapat digunakan sebagai media pembelajaran adalah suara, penglihatan dan gerakan (Sanaky, 2011).

Salah satu aspek utama yang mendukung dalam proses pembelajaran adalah pemilihan media yang tepat sesuai dengan materi pembelajaran yang disampaikan (Andri, 2017). Di masa pandemi seperti saat ini proses pembelajaran harus dilaksanakan dari rumah (work from home) yang dimana siswa juga harus mampu untuk belajar baik secara mandiri maupun didampingi oleh orang tuanya (Damayanti, 2020). Oleh karena itu proses pembelajaran di masa pandemi mewajibkan pengajar untuk lebih interaktif dalam membuat media pembelajaran dalam jaringan agar materi yang disampaikan sesuai dengan capaian pembelajaran (Firmansyah et al., 2020)(Muhajarah \& Sulthon, 2020)

Untuk meningkatkan ketertarikan masyarakat dalam menggunakan bahasa Sunda adalah dengan mempelajarinya secara mudah dan menyenangkan (Mulyati et al., 2019). Oleh karena itu, pada penelitian ini akan dibangun sebuah aplikasi pembelajaran bahasa Sunda secara interaktif dengan memanfaatkan teknologi Google Speech To Text (Pribadi et al., 2016). Google menawarkan beberapa fitur pada Android yang bertujuan untuk membuat suara sebagai alternatif metode input yang layak, misal penelusuran menggunakan suara, input suara ke dalam text field tertentu dan Application 
Programming Interface (API) suara untuk pengembang aplikasi (Supriyanta et al., 2014) (Alawiyah, 2020)

Penelitian ini bertujuan untuk membangun aplikasi berbasis android untuk media pembelajaran bahasa Sunda dengan fitur input suara pengguna dalam bahasa Indonesia. Kemudian aplikasi akan menterjemahkan kata yang diinputkan tersebut menjadi bahasa Sunda. Terdapat juga fitur kebalikannya yaitu dari kata bahasa Sunda ke kata bahasa Indonesia. Manfaat dari aplikasi ini adalah untuk melatih masyarakat mengucapkan kata-kata dalam bahasa Sunda.

\section{B. METODE PENELITIAN}

Dalam penelitian ini, metode penelitian yang digunakan adalah metode deskriptif. Metode deskriptif adalah suatu metode dalam meneliti status sekelompok manusia, suatu objek, suatu set kondisi, suatu sistem pemikiran ataupun suatu kelas peristiwa pada masa sekarang. Dimana tujuan dari metode deskriptif ini untuk membuat deskripsi, gambaran atau lukisan secara sistematis, faktual dan akurat mengenai fakta-fakta, sifatsifat serta hubungan antar fenomena yang diselidiki. Metode deskriptif sesuai untuk diterapkan dalam penelitian ini dengan mengikuti alur atau skema penelitian.

1. Metode Pengumpulan Data

Metode Pengumpulan data yang digunakan yaitu:

a. Studi Lapangan

Studi ini dilakukan dengan cara mengunjungi tempat yang akan diteliti dan melakukan pengumpulan data yang dilakukan secara langsung. Hal ini meliputi:

1. Wawancara

Wawancara adalah salah satu cara pengumpulan data yang dilakukan dilapangan, cara ini untuk mendapatkan data-data primer mengenai bagaimana yang terjadi di masyarakat secara langsung dengan pihak responden terkait dengan penelitian.

2. Kuesioner

Kuesioner adalah teknik pengumpulan data dengan cara survei melalui penyebaran pertanyaan dan keterlibatan responden dalam suatu kelompok diskusi (FGD) dan interview secara mendalam dengan user.

2. Metode Pengembangan Perangkat Lunak

Model yang digunakan dalam pembuatan aplikasi ini adalah model waterfall (Pressman, 2008). Paradigma waterfall ditunjukan pada gambar 1 Model Waterfall. Dalam pembuatan aplikasi ini menggunakan waterfall model sebagai tahapan pembangunan aplikasi, adapun proses tersebut antara lain: 




Gambar 1. Model Waterfall

\section{HASIL DAN PEMBAHASAN}

\section{Analisis Teknologi yang Digunakan}

Google speech API atau Google Voice search diluncrukan pada tahun 2008 di Amerika Serikat untuk beberapa tipe smartphone. Google speech API adalah sebuah framework yang dikembangkan oleh Google untuk mengenali suara, mengubahnya menjadi string (teks) dan memasukkanya ke dalam halaman pencarian Google sehingga akan tampil hasil pencarian berdasarkan input suara. Pengenalan suara dilakukan pada server Google menggunakan algoritma Hidden Markov Model (HMM). Dengan kata lain input suara yang diterima oleh perangkat Android (smartphone) akan dikirimkan ke server Google, yang selanjutnya server Google melakukan pengenalan dan mengubahnya menjadi teks menggunakan algoritma HMM. Hasil konversi suara menjadi teks kemudian dimasukkan dalam halaman pencarian Google kemudian server Google akan mengirimkan hasil pencarianya tersebut ke perangkat Android (Reddy \& Mahender, 2013).

\section{Analisis Arsitektur Sistem}

Tahap analisis ini bertujuan untuk mendapatkan gambaran umum sistem yang akan dibangun. Baik itu gambaran pengguna hingga transaksi data yang akan dibangun. Gambaran arsitektur sistem dari aplikasi yang akan dibangun dapat dilihat pada gambar 2 berikut. 


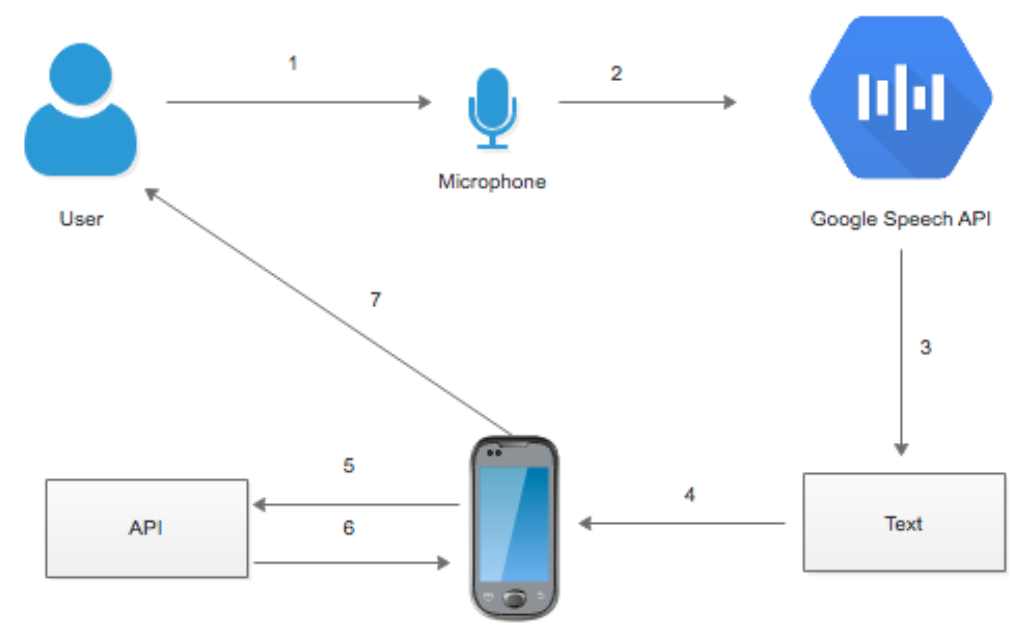

Gambar 2. Arsitektur Sistem yang Dibangun

1. Pengguna melakukan input suara menggunakan microphone yang terpasang pada smartphone android.

2. Sistem mengirimkan suara ke Google Speech API untuk dikonversi menjadi text.

3. Google Speech API memberikan output hasil konversi dari suara ke teks.

4. Sistem menerima data text hasil konversi dari Google Speech API.

5. Sistem melakukan permintaan data hasil terjemahan ke API aplikasi.

6. API memberikan respon permintaan data ke sistem berupa data hasil terjemahan.

7. Sistem menampilkan data kata hasil terjemahan ke pangguna.

\section{Spesifikasi Kebutuhan Perangkat Lunak}

Tabel 1. Spesifikasi Kebutuhan Perangkat Lunak Fungsional

Kode Spesifikasi Kebutuhan Perangkat Lunak SKPL

SKPL-F-01 Sistem menyediakan fasilitas untuk input
suara

SKPL-F-02 Sistem menyediakan fasilitas untuk menerjemahkan kata

SKPL-F-03 Sistem menyediakan fasilitas untuk menampilkan hasil speech to text SKPL-F-04 $\begin{aligned} & \text { Sistem menyediakan fasilitas untuk } \\ & \text { melakukan pencarian kata }\end{aligned}$

Kebutuhan non fungsional pada perangkat lunak yang dibangun dapat dilihat pada tabel berikut

Tabel 2. Spesifikasi Kebutuhan Perangkat Lunak Non Fungsional

\begin{tabular}{cll}
\hline Kode & Spesifikasi Kebutuhan Perangkat Lunak \\
SKPL & \\
\hline SKPL-NF- Sistem yang dibangun membutuhkan \\
01 & $\begin{array}{l}\text { jaringan internet untuk komunikasi data } \\
\text { dengan server }\end{array}$ \\
SKPL-NF- Sistem dibangun dengan spesifikasi
\end{tabular}


02 hardware yang memenuhi standar minimum kebutuhan

SKPL-NF- Desain user interface pada perangkat lunak

03 yang akan dibangun mengacu kepada design guidelines android dari google

\section{Diagram Use Case}

Usecase diagram merupakan alat yang digunakan dalam pengembangan perangkat lunak atau sistem untuk menangkap kebutuhan fungsional dari sistem terkait. Use case diagram menggambarkan sekelompok use case dan aktor yang disertai dengan hubungan diantaranya. Use case diagram ini menjelaskan dan menerangkan kebutuhan yang diinginkan/ dikehendaki user/pengguna, serta sangat berguna dalam menentukan struktur organisasi dan model dari sebuah sistem (M Teguh Prihandoyo, 2018). Pada sistem yang akan dibuat menggunakan use case diagram yang dapat dilihat pada Gambar 3 Usecase Diagram.

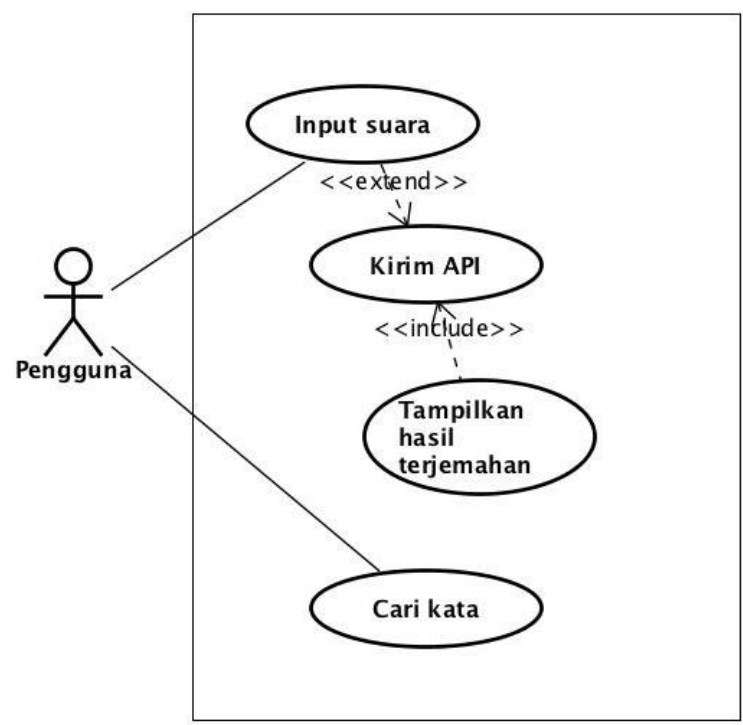

Gambar 3. Use Case Diagram Sistem yang Dibangun

\section{Hasil Implementasi}

Dari analisis pengembangan perangkt lunak yang telah dilakukan, langkah berikutnya adalah proses implementasi sehingga tercipta sebuah sistem atau aplikasi sesuai dengan analisis. Sistem yang berhasil dikembangkan adalah berupa aplikasi pembelajaran bahasa Sunda dengan fitur utama penterjemahan kata menggunakan input suara dengan memanfaatkan teknologi multimedia Google Speech to Text pada perangkat mobile android. Aplikasi dapat dengan mudah diakses dan diunduh karena sudah terpasang di Google Play Store dengan alamat url https://play.google.com/store/apps/details?id=ipi.android.ruangbasa. 


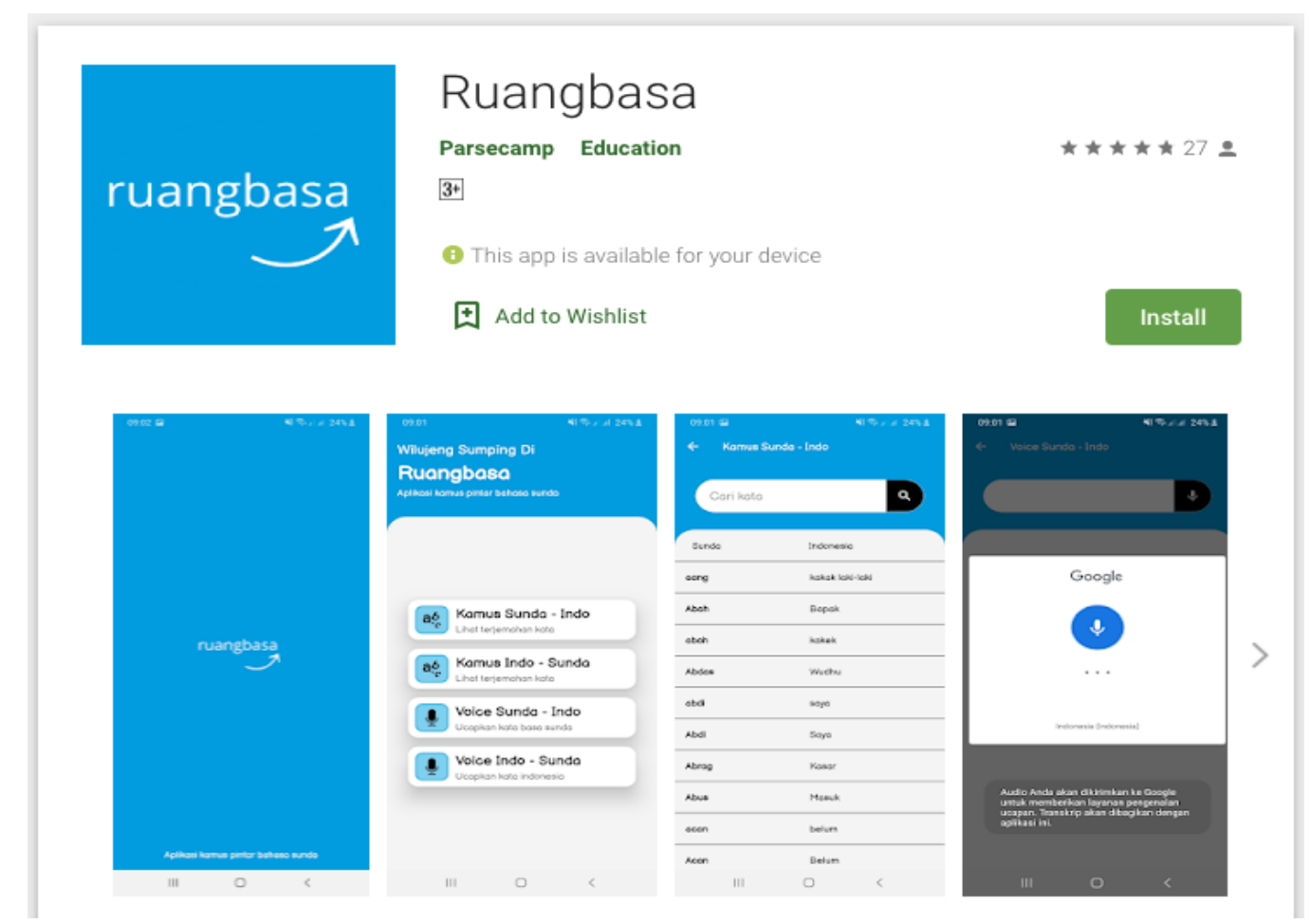

Gambar 4. Tampilan Aplikasi di Google Play Store

Fitur utama yang tersedia pada aplikasi adalah fitur pengucapan kata menggunakan suara untuk mencari terjemahan kata dari bahasa Indonesia ke bahasa Sunda ataupun sebaliknya.

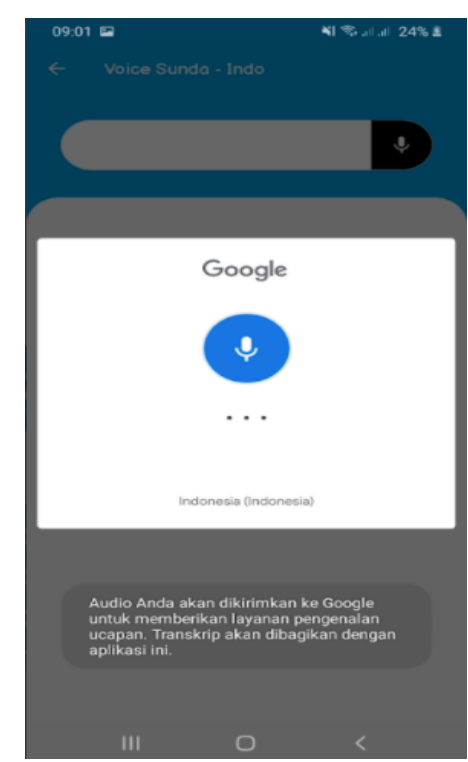

Gambar 5. Tampilan Fitur Speech To Text

Selain itu terdapat fitur kamus kata untuk mencari terjemahan dari bahasa Indonesia ke bahasa Sunda atau sebaliknya dan disediakan menu pencarian kata agar mudah penggunaannya. 


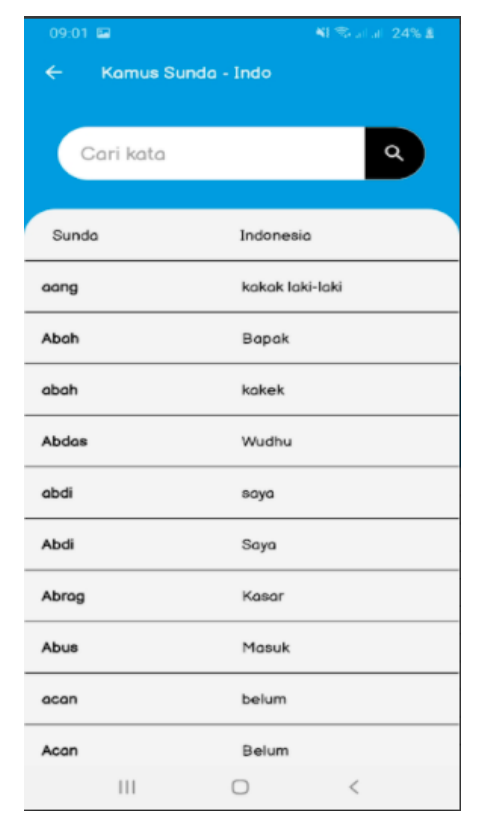

Gambar 6. Tampilan Kamus

\section{Hasil Pengujian}

Tahap yang selanjutnya adalah tahap pengujian sistem pada aplikasi yang dibangun. Tahap ini merupakan hal terpenting yang bertujuan untuk menemukan kesalahan ataupun kekurangan pada aplikasi yang dibangun. Pengujian ini bermaksud untuk mengetahui apakah aplikasi yang dibuat telah memenuhi kriteria yang sesuai dengan tujuan perancangan aplikasi atau belum. Pengujian terhadap sistem aplikasi akan menggunakan strategi pengujian berupa pengujian alpha (black box) dan pengujian beta.

Pengujian dilakukan dengan mencoba semua kemungkinan yang terjadi dan pengujian dilakukan berulang-ulang jika dalam pengujian ditemukan kesalahan maka akan dilakukan penelusuran atau perbaikan untuk memperbaiki kesalahan yang terjadi. Jika telah selesai melakukan perbaikan, maka akan dilakukan secara terus menerus sehingga diperoleh hasil yang terbaik.

Tabel 3. Hasil Pengujian Blackbox

\begin{tabular}{|c|c|c|c|}
\hline Aktivitas Pengujian & $\begin{array}{l}\text { Realisasi yang } \\
\text { Diharapkan }\end{array}$ & $\begin{array}{c}\text { Hasil } \\
\text { Pengujian }\end{array}$ & Kesimpulan \\
\hline Input Suara & $\begin{array}{l}\text { Teks hasil input } \\
\text { suara terdeteksi } \\
\text { Menampilkan }\end{array}$ & $\begin{array}{c}\text { Tertera pada } \\
\text { gambar } 5\end{array}$ & Diterima \\
\hline Pencarian kata & $\begin{array}{l}\text { kata hasil } \\
\text { pencarian }\end{array}$ & $\begin{array}{l}\text { Tertera pada } \\
\text { gambar } 6\end{array}$ & Diterima \\
\hline
\end{tabular}

Hasil pengujian alpha (black box) menyatakan semua fitur yang tersedia pada aplikasi berjalan sesuai yang diharapkan. Selanjutnya hasil pengujian beta telah didapat dari hasil review pengguna di Google Play Store yang memberikan komentar pada aplikasi setelah mereka gunakan. Dari hasil review para pengguna, aplikasi mendapatkan skor 4,8 dari total 27 pengguna. 


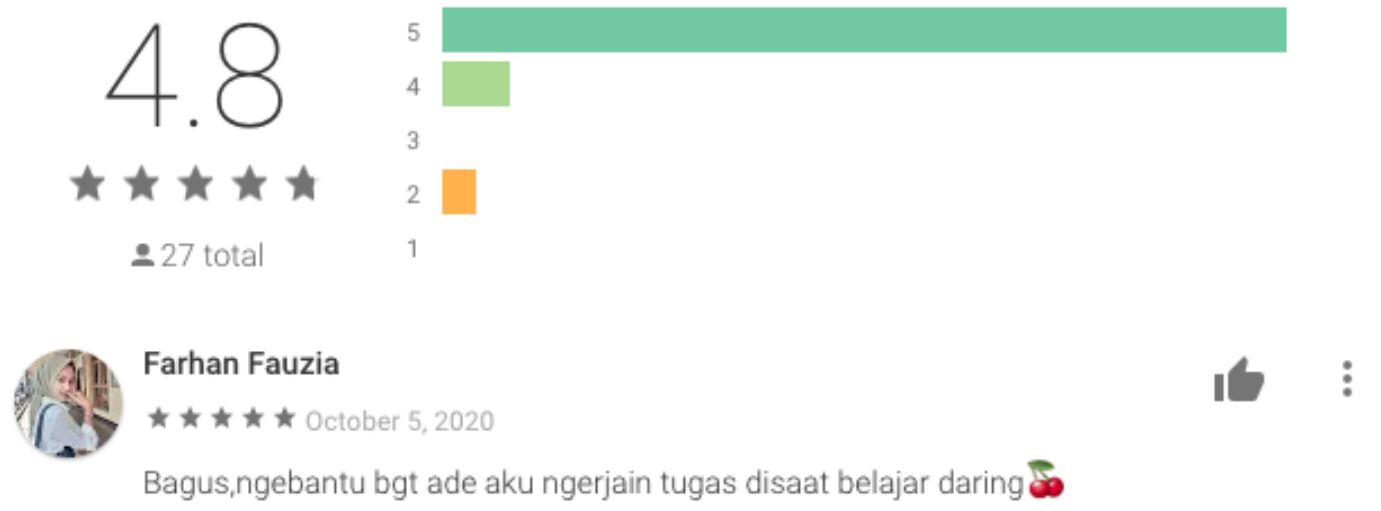

Gambar 7. Tampilan Hasil Review di Google Play Store

\section{SIMPULAN DAN SARAN}

Aplikasi pembelajaran kamus bahasa Sunda ini dapat membantu masyarakat dalam belajar bahasa Sunda. Aplikasi juga sangat mudah digunakan karena adanya fitur multimedia dan berbasis mobile sehingga dapat digunakan dimana saja dan kapan saja. Pengembangan lebih lanjut untuk aplikasi ini adalah dengan tambahan unsur multimedia lainnya agar lebih interaktif misalnya dilengkapi dengan video, animasi, lagu, dan lainnya.

\section{REFERENSI}

Alawiyah, S. (2020). Pembelajaran Online dan Hasil Menulis Karangan Argumentasi di Era Big Data. Justek: Jurnal Sains Dan Teknologi, 3(1), 32. https://doi.org/10.31764/justek.v3i1.3697

Andri, R. M. (2017). Peran dan Fungsi Teknologi Dalam Peningkatan Kualitas Pembelajaran. Jurnal Ilmiah Research Sains, 3(1), 122-129.

Ariyati, S., \& Misriati, T. (2016). Perancangan Animasi Interaktif Pembelajaran Asmaul Husna. Jurnal Teknik Komputer Amik Bsi, II(1), 116-121.

Damayanti, L. S. (2020). Implementasi E-Learning dalam Pembelajaran Bahasa Inggris di Pendidikan Tinggi Pariwisata di Bali Selama Pandemi Covid-19. Journey (Journal of Tourismpreneurship, Culinary, Hospitality, Convention and Event Management), 2(2), 63-82.

Firmansyah, F. H., Fajriyah Aldriani, S. N., \& Dewi, E. R. (2020). Pengembangan Multimedia Pembelajaran Interaktif untuk Mata Pelajaran Matematika untuk Kelas 5 Sekolah Dasar. Edsence: Jurnal Pendidikan Multimedia, 2(2), 101-110. https://doi.org/10.17509/edsence.v2i2.29783

Hakim, L. (2020). Pemilihan Platform Media Pembelajaran Online Pada Masa New Normal. Justek: Jurnal Sains Dan Teknologi, 3(2), 27. https://doi.org/10.31764/justek.v3i2.3516

M Teguh Prihandoyo. (2018). Unified Modeling Language (UML) Model Untuk Pengembangan Sistem Informasi Akademik Berbasis Web. Jurnal Informatika: Jurnal Pengembangan IT, 3(1), 126-129. 
Muhajarah, K., \& Sulthon, M. (2020). Pengembangan Laboratorium Virtual sebagai Media Pembelajaran: Peluang dan Tantangan. Justek: Jurnal Sains Dan Teknologi. https://doi.org/10.31764/justek.v3i2.3553

Mulyati, D., Khairul, A., \& Rahmawati, E. (2019). Perancangan Aplikasi Pengenalan Bahasa Sunda Berbasis Android. Journal of Information Engineering and Educational Technology, 2(2), 101. https://doi.org/10.26740/jieet.v2n2.p101-108

Pramswari, L. P. (2014). Pembelajaran Bahasa Sunda Di Wilayah Perbatasan: Dilema Implementasi Kurikulum 2013. Mimbar Sekolah Dasar, 1(2). https://doi.org/10.17509/mimbar-sd.v1i2.884

Pressman, R. S. (2008). Rekayasa Perangkat Lunak: Pendekatan Praktisi Buku I. Yogyakarta: Andi.

Prihandoyo, M. T. (2018). Unified Modeling Language (UML) Model Untuk Pengembangan Sistem Informasi Akademik Berbasis Web. Jurnal Informatika: Jurnal Pengembangan IT (JPIT), 03(01), 126.

Pribadi, G. E., Syaripudin, U., \& Uriawan, W. (2016). Aplikasi Pembelajaran Bahasa Sunda Dengan Implementasi Algoritma Linear Congruential Generator Dan Fuzzy Berbasis Android. Jurnal Online Informatika, 1(1), 34. https://doi.org/10.15575/join.v1i1.9

Reddy, R. B., \& Mahender, E. (2013). Speech To Text Conversion Using Android Paltform. Internaitonal Journal of Engineering Research and Applicaiton (IJERA) , 3(1), 253258.

Sanaky, H. (2011). Media Pembelajaran. Yogyakarta: Safirina Insania Press.

Supriyanta, Widodo, P., \& Susanto, B. M. (2014). Aplikasi Konversi Suara Ke Teks Berbasis Android Menggunakan Google Speech Api. Bianglala Informatika, 2(2), 1119. 